\title{
Surfactant proteins gene variants in premature newborn infants with severe respiratory distress syndrome
}

\author{
Marco Somaschini ${ }^{1,2} \cdot$ Silvia Presi $^{3} \cdot$ Maurizio Ferrari $^{2,3,4} \cdot$ Barbara Vergani $^{5} \cdot$ Paola Carrera $\mathbb{E}^{2,3}$
}

Received: 29 April 2017 / Revised: 19 October 2017 / Accepted: 26 October 2017 / Published online: 19 December 2017

(c) The Author(s) 2018. This article is published with open access

\begin{abstract}
Objective Genetic surfactant dysfunction causes respiratory failure in term and near-term newborn infants, but little is known of such condition in prematures. We evaluated genetic surfactant dysfunction in premature newborn infants with severe RDS.

Patients and methods A total of 68 preterm newborn infants with gestational age $\leq 32$ weeks affected by unusually severe RDS were analysed for mutations in SFTPB, SFTPC and ABCA3. Therapies included oxygen supplementation, nasal CPAP, different modalities of ventilatory support, administration of exogenous surfactant, inhaled nitric oxide and steroids. Molecular analyses were performed on genomic DNA extracted from peripheral blood and Sanger sequencing of whole gene coding regions and intron junctions. In one case histology and electron microscopy on lung tissue was performed.

Results Heterozygous previously described rare or novel variants in surfactant proteins genes ABCA3, SFTPB and SFTPC were identified in 24 newborn infants. In total, 11 infants died at age of 2 to 6 months. Ultrastructural analysis of lung tissue of one infant showed features suggesting ABCA3 dysfunction.

Discussion Rare or novel genetic variants in genes encoding surfactant proteins were identified in a large proportion (35\%) of premature newborn infants with particularly severe RDS. We speculate that interaction of developmental immaturity of surfactant production in association with abnormalities of surfactant metabolism of genetic origin may have a synergic worsening phenotypic effect.
\end{abstract}

\section{Introduction}

Physiologic transition from foetal to neonatal period requires production of pulmonary surfactant, a complex mixture of phospholipids and proteins that reduces alveolar collapse by decreasing surface tension within the alveoli. Deficiency of pulmonary surfactant due to immaturity is considered the main cause of respiratory distress syndrome

Marco Somaschini

masomaschini@gmail.com

1 Unit of Neonatology, Sant'Anna Clinic, Sorengo, Switzerland

2 Unit of Genomics for the Diagnosis of Human Pathologies, Division of Genetics and Cell Biology, IRCCS San Raffaele Scientific Institute, Milan, Italy

3 Clinical Molecular Biology Laboratory, IRCCS San Raffaele Scientific Institute, Milan, Italy

4 Vita-Salute San Raffaele University, Milan, Italy

5 Microscopy and Image Analisys Consortium, University of Milano-Bicocca, Monza, Italy
(RDS), a multifactorial disease characterised by respiratory failure and altered gas exchange [1]. However, lethal mutations in surfactant genes in term and near-term newborns support the notion of a genetic contribution to RDS $[2,3]$. Surfactant proteins represent a small percentage in surfactant composition but they are essential for surfactant homeostasis. In particular, surfactant protein B (SP-B) and $\mathrm{C}$ (SP-C) are essential for tensioactive properties of pulmonary surfactant, whereas ATP-binding cassette 3 (ABCA3) participates in the transport of phospholipids and cholesterol to lamellar bodies, the organelles where surfactant is stored before secretion in the alveolus. Pathogenic variants in genes encoding SP-B and ABCA3 result in severe and often fatal lung disease transmitted as a recessive trait in neonates [4-8]. In addition, recessive and dominant pathogenic variants in ABCA3 and SFTPC genes, respectively, have been associated with chronic interstitial lung disease (ILD) in term newborns, children and adults $[9,10]$.

Little is known about the correlation of variants in genes encoding surfactant proteins in premature newborn infants with severe RDS, since the majority of genetic tests are 
requested on term newborns with unexplained RDS. In this study we analysed the genes encoding protein B (SFTPB), $\mathrm{C}(S F T P C)$ and $\mathrm{ABCA} 3(A B C A 3)$ in premature infants with gestational age $\leq 32$ weeks presenting a particularly severe course of RDS.

\section{Patients and methods}

We retrospectively reviewed molecular analyses of premature newborn infants presenting particularly severe RDS referred to our laboratory of Molecular Biology from 2005 to 2016, performed for diagnostic purposes. All the examined subjects gave their written informed consent for genetic testing, data treatment and storage, approved by the Institutional Quality Assessment Committee.

Sixty-eight preterm newborn infants with gestational age $\leq 32$ weeks and birth weight ranging from 550 to $1900 \mathrm{~g}$, affected by particularly severe RDS, were analysed by Sanger sequencing in the SFTPB, SFTPC and ABCA3. Treatments included prolonged oxygen supplementation, respiratory support with CPAP, conventional mechanical ventilation, high frequency oscillatory ventilation (HFOV), exogenous surfactant administration, inhaled nitric oxide, postnatal steroids administration and home oxygen supplementation. Severity of the disease was based on the clinical judgement of the treating neonatologist.

\section{Molecular analysis}

Molecular analyses were performed on genomic DNA extracted from peripheral blood leukocytes by a Maxwell 16 extractor (Promega Co., WI USA) or by conventional phenol-chloroform method. All exonic and flanking regions of SFTPB, SFTPC and ABCA3 genes were amplified by polymerase chain reaction (PCR) and directly sequenced using the Sanger method on a 3730 Applied Biosystems automatic sequencer. The PCR purification and dye removal steps were performed on a Biomek FX Laboratory Automation Workstation (Beckman Coulter) with AmPure and CleanSeq kit (Agencourt-Beckmann Coulter) respectively.

Using the Gene Codes Sequencer software (V.5.0), called sequences were aligned to each gene reference sequence: SFTPB: ENSG00000168878 and ENST00000409383; SFTPC: ENSG00000168484 and ENST00000318561; ABCA3: ENSG00000167972 and ENST00000301732.

All identified variants were described in accordance with the 'Human Genome Variation Society' nomenclature. Gene variants were evaluated by their absence or frequency in the dbSNP, 1000 Genomes, ExAc, gnomAD databases. The HGMD professional 2016.4 database and PubMed were interrogated to check for already described variants. The
PolyPhen2, SIFT, Grantham distance, Align GVGD, were used to predict the functional effect of missense changes. Human Splicing Finder, Gene Splicer, MaxEntScan, NNSplice and Splice Site Prediction by Neural Network were used to predict the potential effect on splicing. Classification of the variants was performed based on the ACMG-AMP criteria [11].

\section{Immunohistochemical analysis}

Immunohistochemical analysis was carried out on 4 micron, formalin-fixed, paraffin-embedded sections. Samples were deparaffined in xylene and grades of alcohol, then rehydrated in water and were incubated whit a polyclonal antibody to ABCA3 at a dilution of 1:30 (Atlas Antibodies, St Louis, MO,USA). Antigen retrieval was performed by heating in a pressure cooker with Citrate buffer for $15 \mathrm{~min}$. A polymer detection methods (Thermo Fisher Scientific, Fremont,CA,USA) followed by a brown chromogen solution was used for detection.

\section{Electron microscopy}

In one infant, who deceased at the age of 4 months, lung tissue was examined with electron microscopy. For ultrastructural studies, lung fragments were either fixed in $2.5 \%$ glutaraldehyde in $0.1 \mathrm{M}$ cacodylate buffer ( $\mathrm{pH} 7.2$ ), postfixed in osmium tetroxide and processed into epoxy resin. Ultrathin sections were obtained from several blocks, stained with lead citrate and uranyl acetate, and observed with a Philips CM10 transmission electron microscope.

\section{Results}

Overall, 28 rare or novel variants of $A B C A 3, S F T P B$ and SFTPC were identified in 24 infants (Tables 1 and 2), with the exclusion of common variants. In particular, 7 were novel while the remaining were rare variants. $A B C A 3$ was the most frequently affected gene with 21 variants in 18 neonates. In the six newborns without variants in ABCA3, variants in $S F T P B$ or $S F T P C$ were present. In case n.2 variants in both $A B C A 3$ and $S F T P B$ were identified. By looking at the variants, one in-frame deletion, 9 missense, 4 synonymous, 12 intronic and 2 variants in the $3^{\prime} \mathrm{UTR}$ were found. By applying ACMG-AMP criteria for interpretation of sequence variants, all of them have been classified as variants of unknown significance. Nevertheless based on the nature and location of the variant, the in silico analysis, the population frequency and critical analysis of the literature we can speculate on which variants may have 


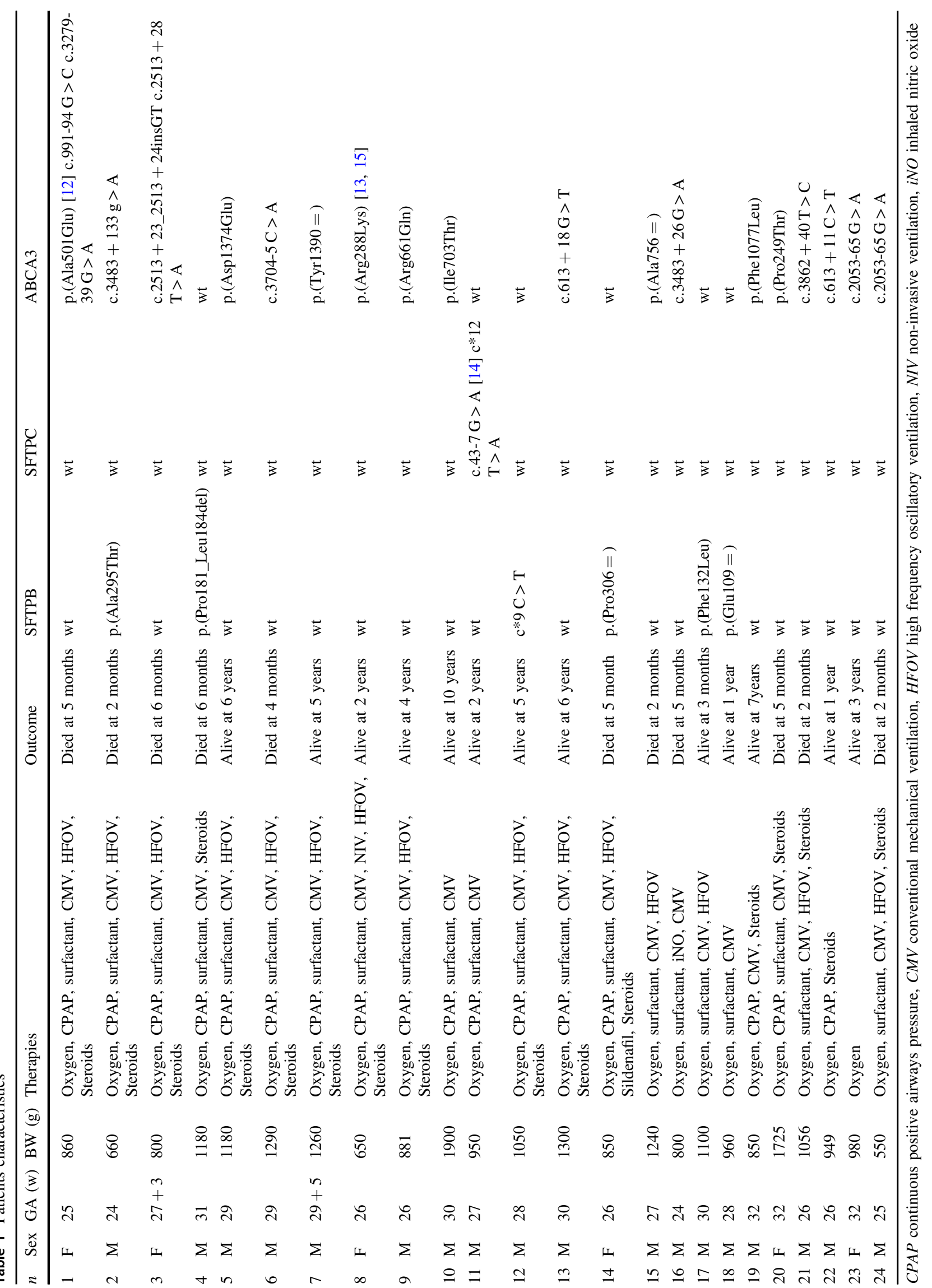




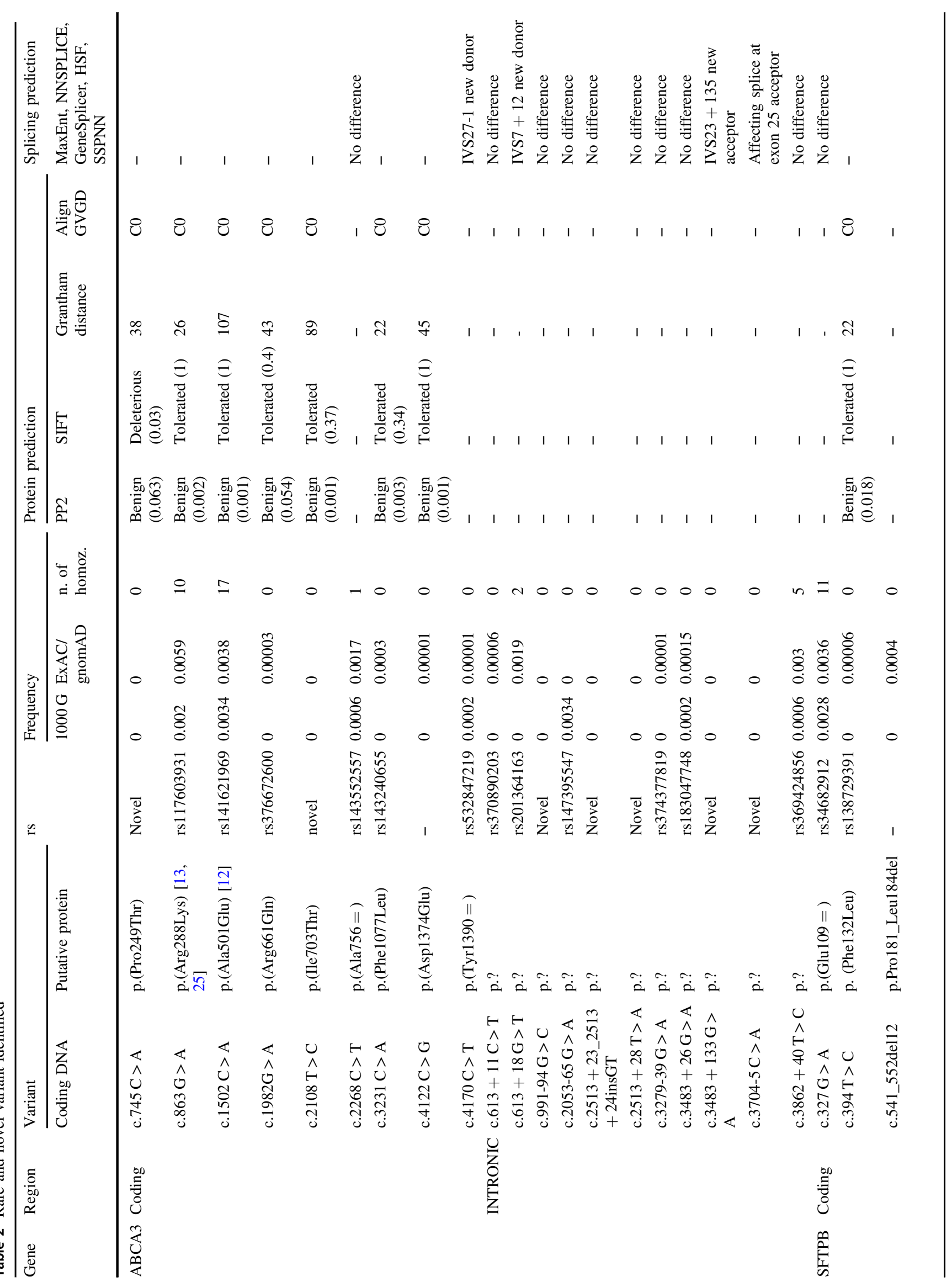




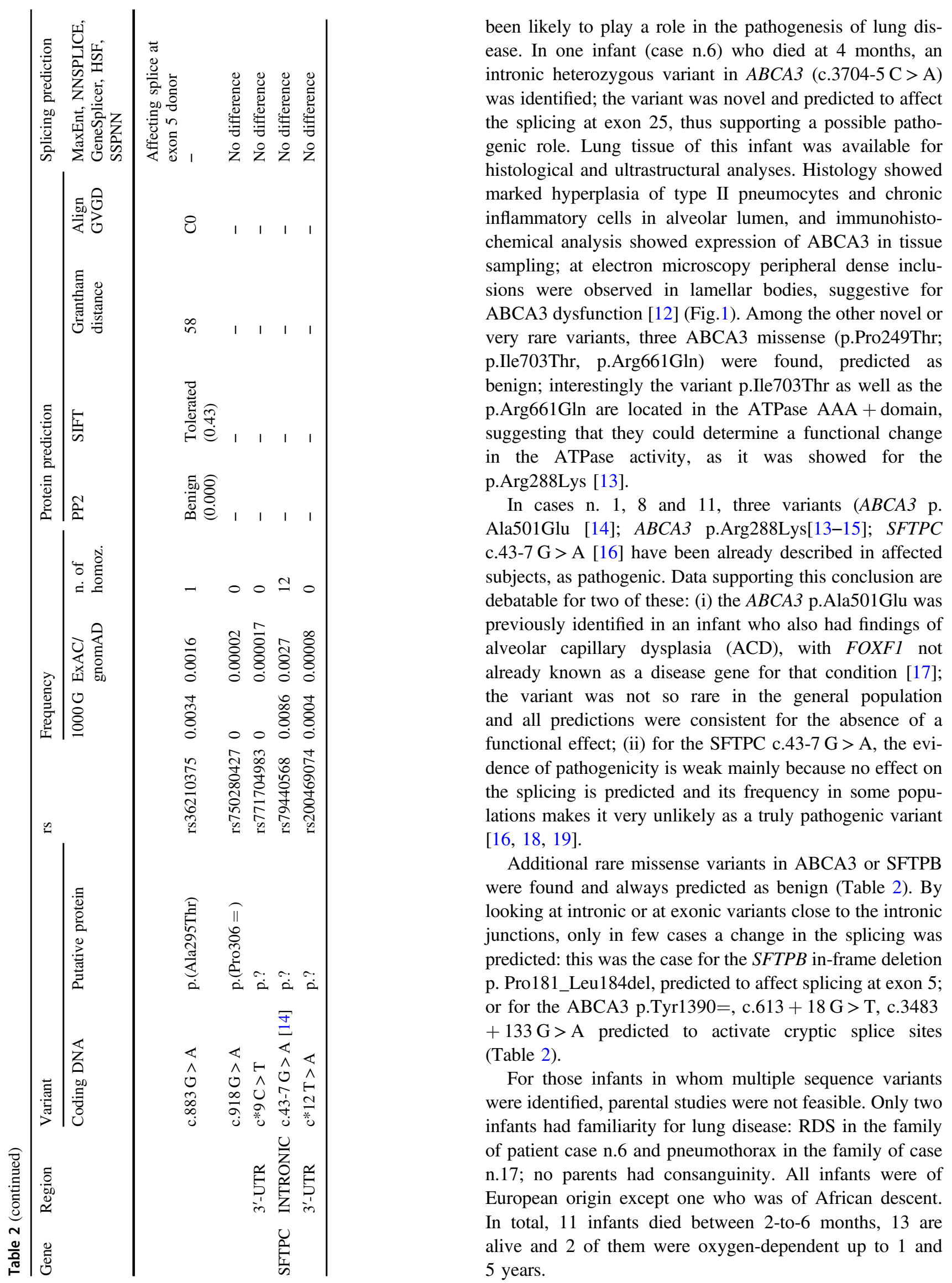




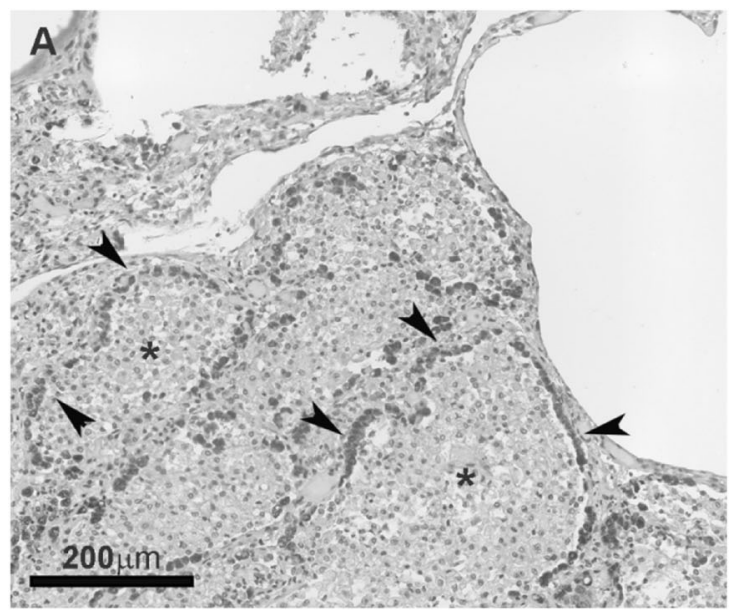

Fig. 1 Immunohistochemistry and EM analysis of case $\mathrm{N}^{\circ} 6$ a representative immunohistochemical staining with ABCA3 antibody (brown colour) showing aType II pneumocyte hyperplasia

\section{Discussion}

RDS is a complex disease and several factors may contribute to its aetiology. The major pathogenic factor of RDS is a lack of pulmonary surfactant due to developmental immaturity of the lungs. However, genetic mechanisms may contribute significantly to development of neonatal RDS [2]. Pathogenic variants in $S F T P B, S F T P C$ and $A B C A 3$ transmitted in a Mendelian pattern cause severe or lethal RDS in term newborn infants. Sequencing of $S F T P B$, SFTPC and ABCA3 allowed us to identify 28 single base substitutions or small indels in 24 preterm newborn infants, while we did not excluded the presence of large structural variants or the presence of pathogenic variants in other genes, not exclusively associated with Respiratory Distress (i.e., NKX2-1, OMIM600635).

In relation to the rare and novel variants reported in the present study, we referred our comparison to the data on the general population frequencies, available in the genomic public databases (Table 2). The ideal control group would have be a population of infants matched for ethnicity and gestational age without lung disease or with mild RDS, but unfortunately this group was not available.

Overall, rare or novel gene variants were found in 24 patients out of the 68 examined (35.3\%). By focusing on variants with a lower frequency in the general population, a predicted effect or located in a functional domain, we can restrict to 11 stronger candidate variants, corresponding to $16.2 \%$. None of the study subjects had a diagnosis of a surfactant dysfunction disorder clearly established by genetic testing, nevertheless our results, indicating an overrepresentation of possibly deleterious alleles, support the findings of previous studies. Partial SP-B deficiency due to a single SP-B gene variant was reported in a term neonate

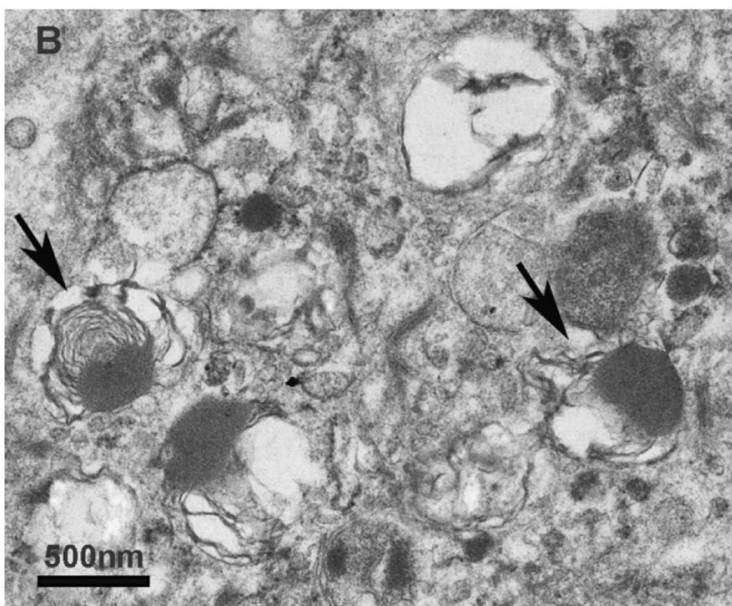

(arrowhead). Lumen contains chronic inflammatory cells (asterisk). b Electron microscopy shows lamellar bodies electron-dense aggregates in the form of 'fried egg' with an asymmetric core (arrows)

who survived developing chronic lung disease with prolonged oxygen-dependency [20]. Experimental data indicate that partial SP-B deficiency increases susceptibility to lung injury. Animal studies in genetically engineered mice, in which SP-B can be reduced, indicated that a level of SPB production of $20-30 \%$ of control level is needed for normal lung function [21]. Mice heterozygous for a null SP$\mathrm{B}$ allele showed an increased susceptibility to oxygeninduced lung injury: a decrease in lung compliance was associated with increased severity of pulmonary oedema, haemorrhage and inflammation, lung permeability, and protein leakage into the alveolar space. It was likely that partial SP-B deficiency resulted in instability of affected alveoli, leading to micro-atelectasis, a decrease in residual lung volume and air space enlargement detected in histological sections [22, 23]. Therefore, infants who are heterozygous for pathogenic variants can be at risk for lung disease if other environmental factors such as prematurity further reduce SP-B expression.

Moreover, Wambach et al. showed that single $A B C A 3$ mutations are overrepresented among European descent infants $\geq 34$ weeks of gestation with RDS and account for $10.9 \%$ of the attributable risk among term and late preterm infants. Because ABCA3 expression is developmentally regulated, a single mutation coupled with developmental immaturity could reduce ABCA3 expression below a functional threshold that results in RDS [24]. One specific single mutation of $A B C A 3$ (p.Glu292Val) was found to be at increased risk for developing pneumo-thoraces and the phenotype of ILD. The authors hypothesised that the p. Glu292Val change could in part increase sensitivity to the developmental risk of RDS [25]. Index patient n. 6 presented a single intronic variant in $A B C A 3$ and died at 4 months; ABCA3 was detected at immunohistochemical 
staining of the lung tissue, however type II pneumocytes hyperplasia, inflammatory cells infiltration and the presence of peripheral dense aggregates in lamellar bodies at electron microscopy may suggest a disorder in surfactant metabolism [26, 27]. (Fig. 1). SFTPC mutations are responsible of ILD in infants and children with onset of symptoms after the neonatal period; however, sometimes they become symptomatic in the neonatal period [3].

Our study shows that candidate variants in surfactant protein genes were identified also in newborn infants of gestational age $\leq 32$ weeks with particularly severe RDS, even without consanguinity and positive family history, suggesting that prematures could be affected not only by an insufficient amount of pulmonary surfactant due to pulmonary immaturity, but also by abnormalities of surfactant metabolism and function of genetic origin. In our cohort, a common clinical characteristic of infants was the perception that the clinical course of RDS was more severe, complicated or prolonged than usual. Infants showed poor response to surfactant administration, difficulty of weaning from mechanical ventilation, need of unconventional ventilatory support or prolonged oxygen dependency. In total, 11 infants died within the first 6 months, 13 survived and 2 were oxygen dependent after discharge from the hospital for 1 and 5 years (Table 1). Our study is not population-based and we do not know if all neonates with very severe respiratory failure were referred for genetic testing, precluding estimates of the incidence of these disorders.

We speculate that premature newborn infants with a single pathogenic variant in surfactant protein genes may have a reduced production or impaired function of the protein that, in conjunction with pulmonary immaturity, increases severity of the lung disease, thus behaving as a multifactorial disorder.

Testing for surfactant dysfunction is currently recommended in term neonates of more than 37 weeks gestation who develop unexplained respiratory distress, or of earlier gestational age when there is a positive family history and consanguinity [28, 29]. Extension of genetic testing for surfactant dysfunction in premature newborn infants with a worse phenotype of RDS, regardless of familiarity for lung diseases or consanguinity, to allow better prognostication, a more conscious choice of therapeutic options and eventually genetic counselling, seems to be useful but more challenging. Our findings outlined our still limited knowledge and difficulty in interpretation of genetic variants, since genetic testing was not conclusive and, as previously reported, this point is one of the main issues of genetic testing. Moreover due the high cost of molecular testing, it is not sustainable by health care systems for all the patients. Further studies are needed to improve our knowledge on genetic variants and understanding of the mechanisms that regulate surfactant metabolism in term and preterm newborn infants with unexplained and severe RDS.

\section{Compliance with ethical standards}

Conflict of interest The authors declare that there is no conflict of interest.

Open Access This article is licensed under a Creative Commons Attribution-NonCommercial-NoDerivatives 4.0 International License, which permits any non-commercial use, sharing, distribution and reproduction in any medium or format, as long as you give appropriate credit to the original author(s) and the source, and provide a link to the Creative Commons license. You do not have permission under this license to share adapted material derived from this article or parts of it. The images or other third party material in this article are included in the article's Creative Commons license, unless indicated otherwise in a credit line to the material. If material is not included in the article's Creative Commons license and your intended use is not permitted by statutory regulation or exceeds the permitted use, you will need to obtain permission directly from the copyright holder. To view a copy of this license, visit http://creativecommons.org/licenses/by-nc-nd/4.0/.

\section{References}

1. Avery ME, Mead J. Surface properties in relation to atelectasis and hyaline membrane disease. AMA J Dis Child. 1959; 97:517-23.

2. Clark H, Clark LS. The genetics of neonatal respiratory disease. Semin Fetal Neonatal Med. 2005;10(3):271-82.

3. Wert SE, Whittsett JA, Nogee LM. Genetic disorders of surfactant dysfunction. Pediatr Dev Pathol. 2009;12(4):253-74.

4. Nogee LM. Genetic mechanisms of surfactant deficiency. Biol Neonate. 2004;85:314-8.

5. Whitsett JA, Wert SE, Trapnell BC. Genetic disorders influencing lung formation and function at birth. Hum Mol Genet. 2004; 13:207-15

6. Nogee LM, deMello DE, Dehner LP, Colten HR. Deficiency of pulmonary surfactant protein $\mathrm{B}$ in congenital alveolar proteinosis. N Engl J Med. 1993;328:406-10.

7. Shulenin S, Nogee LM, Annilo T, Wert SE, Whitsett JA, Dean M. ABCA3 gene mutations in newborns with fatal surfactant deficiency. N Engl J Med. 2004;350:1296-303.

8. Somaschini M, Nogee LM, Sassi I, Danhaive O, Presi S, Boldrini $\mathrm{M}$, et al. Unexplained neonatal respiratory distress due to congenital surfactant deficiency. J Pediatr. 2007;150:649-53.

9. Nogee LM, Dunbar AE, Wert SE, Askin F, Hamvas A, Whitsett JA. A mutation in the surfactant protein $\mathrm{C}$ gene associated with familial interstitial lung disease. N Engl J Med. 2001;344:573-9.

10. Bullard JE, Wert SE, Whitsett JA, Dean M, Nogee LM. ABCA3 mutations associated with pediatric interstitial lung disease. Am J Respir Crit Care Med. 2005;172:1026-31.

11. Richards S, Aziz N, Bale S, Bick D, Das S, Gastier-Foster G, et al. Standards and guidelines for the interpretation of sequence variants: a joint consensus recommendation of the American College of Medical Genetics and Genomics and the Association for Molecular Pathology. Genet Med. 2015;17:405-24.

12. Edwards V, Cutz E, Viero S, Moore AM, Nogee L. Ultrastructure of lamellar bodies in congenital surfactant deficiency. Ultrastruct Pathol. 2005;29:503-09.

13. Wambach JA, Yang P, Wegner DJ, Heins HB, Kaliberova LN, Kaliberov SA, et al. Functional characterization of ATP-binding 
cassette tansporter A3 mutations from infants with respiratory distress syndrome. Am J Respir Cell Mol Biol. 2016;55:716-21.

14. Brasch F, Schimanski S, Mühlfeld C, Barlage S, Langmann T, Aslanidis $\mathrm{C}$, et al. Alteration of the pulmonary surfactant system in full-term hereditary ABCA3 deficiency. Am J Respir Crit Care Med. 2006;174:571-80.

15. Copertino M, Barbi E, Poli F, Zennaro F, Ferrari M, Carrera P, et al. A child with severe pneumomediastinum and ABCA3 gene mutation: a puzzling connection. Arch Bronconeumol. 2012; 48:139-40.

16. Lawson WE, Grant SW, Ambrosini V, Womble KE, Dawson EP, Lane $\mathrm{KB}$, et al. Genetic mutations in surfactant protein $\mathrm{C}$ are a rare cause of sporadic case of IPF. Thorax. 2004;59:977-80.

17. Danhaive O, Peca D, Boldrini R. ABCA3 mutation and pulmonary hypertension: a link with capillary dysplasia? J Pediatr. 2008;152:891-2.

18. Tarocco A, Ballardini E, Contiero MR, Garani G, Fanaro S. Two mutations in surfactant protein $\mathrm{C}$ gene associated with neonatal respiratory distress. Case Rep Pediatr. 2015; 2015:591783.

19. Abouelhoda M, Faquih T, El-Kalioby M, Alkuraya FS. Revisiting the morbid genome of Mendelian disorders. Genome Biol. 2016;17:235.

20. Klein JM, Thompson MW, Snyder JM, George TN, Whitsett JS, Bell EF, et al. Transient surfactant protein B deficiency in a term infant with severe respiratory failure. J Pediatr. 1998;132:244-48.

21. Melton KR, Nesslein LL, Ikegami M, Tichelaar JW, Clark JC, Whitsett JA, et al. SP-B deficiency causes respiratory failure in adult mice. Am J Physiol. 2003;285:L543-9.
22. Tokieda K, Iwamoto HS, Bachurski C, Wert SE, Hull WM, Whitsett JA, et al. Surfactant protein-B-deficiency mice are susceptible to hyperoxic lung injury. Am J Respir Cell Mol Biol. 1999;463:463-72.

23. Nesslein LL, Melton KR, Ikegami M, Wert SE, Rice WR, Whitsett JA, et al. Partial SP-B deficiency perturbs lung function and causes air space abnormalities. Am J Physiol Lung Cell Mol Physiol. 2005;288:L1154-61.

24. Wambach JA, Wegner DJ, DePass K, Heins H, Druley TE, Mitra RD, et al. Single ABCA3 mutations increase risk for neonatal respiratory distress syndrome. Pediatrics. 2012;130: e1575-82.

25. Garmany TH, Wambach JA, Heins HB, Watkins-Torry JM, Wegner DJ, Bennet k, et al. Population and disease-based prevalence of the common mutations associated with surfactant deficiency. Pediatr Res. 2008;63(6):645-49.

26. Jackson T, Wegner DJ, White FV, Hamvas A, Cole FS, Wambach JA. Respiratory failure in a term infant with cis and trans mutations in ABCA3. J Perinatol. 2015;35(3):231-2.

27. Doan ML, Guillerman RP, Dishop MK, Nogee LM, Langston C, Mallory GB, Sockrider MM, Fan LL. Clinical, radiological and pathological features of $\mathrm{ABCA} 3$ mutations in children. Thorax. 2008;63(4):366-73.

28. Gower WA, Nogee LM. Surfactant dysfunction. Pediatr Respir Rev. 2011;12(4):223-29.

29. Turcu S, Ashton E, Jenkins L, Gupta A, Mok Q. Genetic testing in children with surfactant dysfunction. Arch Dis Child. 2013;98:490-96. 